\title{
Modeling, design and control of low-cost Remotely Operated Vehicle for shallow water survey
}

\author{
Tran Ngoc Huy ${ }^{*}$, Huynh Tan Dat
}

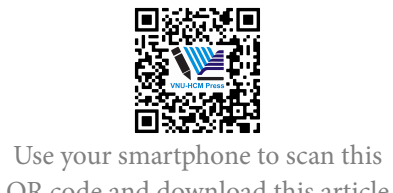

QR code and download this article

\begin{abstract}
Shallow water zones including lakes, ponds, creeks, and rivers play a prominent role in the spiritual culture and economy of Vietnamese people throughout history. Therefore, numerous researches have been conducted in regard to this topic for many purposes, most of which focus on elevating the quality of life and safety. With the aid of new technology, modern platforms gradually replace conventional methods and reach a higher level of efficiency and convenience. This paper presents the research on design and control of Remotely Operated Vehicle (ROV) belonging to National key Laboratory of Digital Control and System Engineering. Basically, it is controlled by human pilots to move underwater and perform specifically pre-assigned tasks. The power supply and communication channel for the vehicle are connected from an onshore station via cable systems. There are several stages of the pipeline in implementing a full-scale ROV platform that must be studied carefully. Prior to the experiments in practical conditions, th e proposed 3D model designed by SOLIDWORKS ${ }^{\circ}$ and MATLAB Simulink ${ }^{\circ}$ mathematical model analysis firstly provide a nonlinear plant in order to apply classical PID controllers and evaluate their feasibility through simulation process. The outer frame protects other components from being damaged or unattached while the thruster allocation strategy from the simulated model enables flexibility in motion. A system of sensors and camera collects data from underwater environment for on-the-spot monitoring or they can be captured for further post-analysis processes. After assembling all parts into a whole model, we launched the vehicle at the maximum depth of a pool as the condition of a shallow water survey. Optimistic experimental results have proved the ability of controllers even in case of the presence of external disturbances.

Key words: Remotely Operated Vehicle, PID controller, underwater robot
\end{abstract}

\section{INTRODUCTION}

Ho Chi Minh city University of

Technology, VNU-HCM

Correspondence

Tran Ngoc Huy, Ho Chi Minh city University of Technology, VNU-HCM

Email: tnhuy@hcmut.edu.vn

History

- Received: 10/01/2019

- Accepted: 16/3/2019

- Published:31/12/2019

DOI : 10.32508/stdjet.v3iSI1.722

\section{Check for updates}

\section{Copyright}

(.) VNU-HCM Press. This is an openaccess article distributed under the terms of the Creative Commons Attribution 4.0 International license.

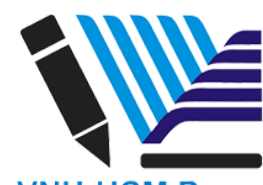

VNU-HCM Press
Vietnam is a coastal country which is packed with activities in national defense, economy, environment and tourism. In areas with an exceptional depth or harsh natural environmental conditions, people can not handle difficult tasks. Therefore, the development of underwater vehicles to support and gradually replace human factor is essential to ensure the workplace safety while performing given tasks according to technical requirements. There are two types of diving robots: Remotely Operated Vehicle Control (ROV) and Autonomous Underwater Vehicle (AUV) ${ }^{1}$. Although AUV is capable of working automatically, ROV provides on-the-spot surveillance without being limited by operation time due to the direct power supply and communication through cables. With the addition of accessories such as grabber, water sampling module will aid ROV in carrying out simple tasks. In this research, the $3 \mathrm{D}$ mechanical model is designed based on reference from previous related works, using SolidWorks software ${ }^{2}$. Simulation for mathematical model using MATLAB Simulink will be performed to observe the response of position, velocity and acceleration values over time. Based on the defined parameters in ${ }^{3}$, classical PID controllers were studied to evaluate the ability to control ROV in practice. The output of this research is a ROV model for actual tests, applying the programmed controller.

\section{METHODOLOGY}

\section{Design of 3D model}

The design concept for ROV varies according to size, weight and function. However, a typical ROV should consist of a mechanical frame, thrusters, power supply system, communication and control module as well as image capture function. Some of basic specifications are listed below.

- Box frame configuration

- Estimated operating depth: $5 \mathrm{~m}$

- Average speed: $0.5 \mathrm{~m} / \mathrm{s}$

- Continuous operation with DC Power Supply 
- Number of thrusters: 6

- Weight (in air): $25 \mathrm{~kg}$

Figure 1 and Figure 2 display the ROV model in three dimensional spaces, designed by SolidWorks. Apart from the outer frame and thrusters, other components are placed in waterproof function boxes.

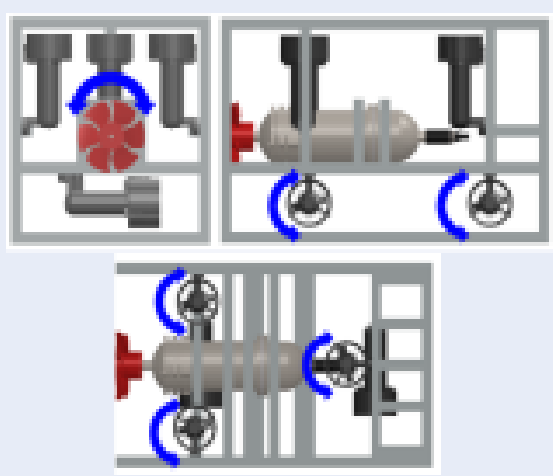

Figure 1: Thrusters arrangement in back view, side view and top view respectively.

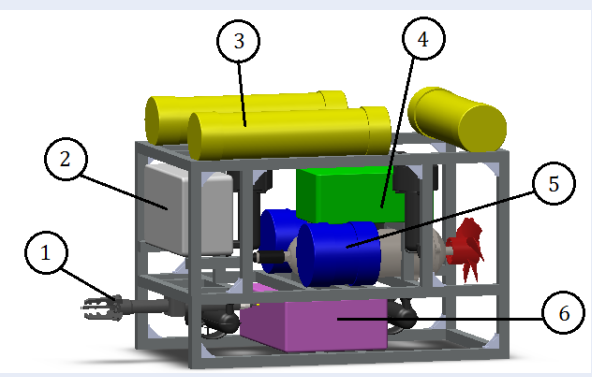

Figure 2: Overall 3D ROV model.

In the above figure, the numbered components can be sequentially expressed in detail:

1. Three jaw grabber

2. Camera and lighting system box

3. Buoyancy system

4. Sensors box

5. Water sampling module

6. Power supply and thruster's drive box

A brief description of components is given subsequently. The vehicle is equipped with a grabber for a wide array of useful tasks such as carrying or recovering objects underwater. An integrated camera captures image signals with the aid of high performance lights then feedbacks those to the central processing unit, all just within a box. Three PVC pipes form a floating plane, keeping ROV's self-balance at rest on water surface. The sensors box contains some navigation sensors used to determine the orientation of ROV to control thruster properly. In addition, a watersampling module can collect an amount of water at a desired depth for environmental quality analysis. The last and most important component is an aluminum container that converts high DC voltage from the cable into 24 and 48 DCV for power supply while transferring heat to surrounding water in order to protect and stabilize power converter circuits.

\section{Coordinate system and definition of kine- matic notations}

To explain the motion of ROV in six degrees of freedom and to determine position and orientation in three-dimensional space, it is essential to define coordinate system and notations. Kinematics from ROV base on two types of reference, which are earth-fixed coordinate system (NED) with arbitrary origin $\mathrm{O}_{n}$ and body-fixed coordinate system (BODY) with the origin $\mathrm{O}_{b}$ placed at the center of gravity ${ }^{4}$. Meanwhile, the notations which are used to explain ROV motion are summarized in Table 1.

Table 1: Notations of 6-DOF Standard motions

\begin{tabular}{ccccc}
\hline DOF & $\begin{array}{c}\text { Mo- } \\
\text { tions }\end{array}$ & $\begin{array}{c}\text { Forces } \\
\text { and } \\
\text { Moments } \\
(\tau)\end{array}$ & $\begin{array}{c}\text { Linear and } \\
\text { Angular } \\
\text { velocities } \\
(v)\end{array}$ & $\begin{array}{c}\text { Positions } \\
\text { and Orien- } \\
\text { tations } \\
(\eta)\end{array}$ \\
\hline 1 & Surgt & X & u & x \\
2 & Sway & Y & v & y \\
3 & Heav & Z & w & Z \\
4 & Roll & K & p & $\phi$ \\
5 & Pitch & M & q & $\theta$ \\
6 & Yaw & N & r & $\psi$ \\
\hline
\end{tabular}

Vector $\eta$ is in the reference of inertial earth-fixed coordinate system, whereas the velocity vector $v$ and external force and moment vector $\tau$ that acts on ROV body must be expressed in BODY reference frame. Figure 3 shows the relation between those two coordinate systems.

\section{Mathematical model of ROV}

Mathematical model of ROV can be obtained in terms of kinematic and dynamic equations. When studying about motion of object without regard to the forces or 


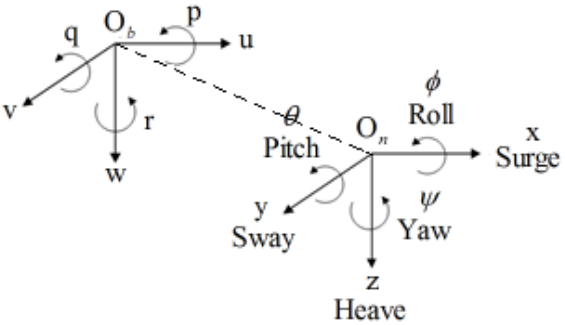

Figure 3: Earth-fixed to body-fixed coordinate system.

moments, kinematic equation can be written state parameters. As mentioned before, the Jacobian matrix must be used to transform from earth-fixed frame to body-fixed frame.

$$
\begin{gathered}
\eta=J(\eta)_{V} \\
J\left(\eta_{2}\right)=\left[\begin{array}{cc}
J_{1}(\eta) & 0 \\
0 & J_{2}(\eta)
\end{array}\right] \\
J_{1}(\eta)=\left[\begin{array}{cc}
c \psi c \theta & -s \psi c \phi+c \psi s \theta s \phi \\
s \psi c \theta & c \psi c \phi+s \phi s \theta s \psi \\
-s \theta & c \theta s \phi \\
& s \psi s \phi+c \psi c \phi s \theta \\
& -c \psi s \phi+s \theta s \psi c \phi \\
& c \theta c \phi
\end{array}\right] \\
J_{2}(\eta)=\left[\begin{array}{ccc}
1 & s \phi t \theta & c \phi t \theta \\
0 & c \phi & -s \phi \\
0 & s \phi / c \theta & c \phi / c \theta
\end{array}\right]
\end{gathered}
$$

Based on Newton's Second Law, if the forces that act upon an object are considered, the derivative dynamic equation is expressed for the complete three dimensions, 6 DOF rigid body motion as follows:

$$
M \dot{v}+C(v) v+D(v) v+g(\eta)=\tau
$$

The right-hand side refers to the input forces and moments to the ROV, including thruster forces, disturbances, environmental forces (wind, wave and ocean current). For the most basic control, let $\tau=[\mathrm{X}, \mathrm{Y}, \mathrm{Z}$, $\mathrm{K}, \mathrm{M}, \mathrm{N}]^{T}$ denotes the specific forces and moments vector of ROV only from thrusters. It can be obtained from the multiplication of component thruster forces vector $\mathrm{u}=\left[\mathrm{F}_{1}, \mathrm{~F}_{2}, \mathrm{~F}_{3}, \mathrm{~F}_{4}, \mathrm{~F}_{5}, \mathrm{~F}_{6}\right]^{T}$ by a thruster's configuration matrix $\mathrm{B}^{3}$, according to the position of each thruster where $l_{1}=10 \mathrm{~mm}, l_{2}=150 \mathrm{~mm}, l_{3}=140 \mathrm{~mm}$,

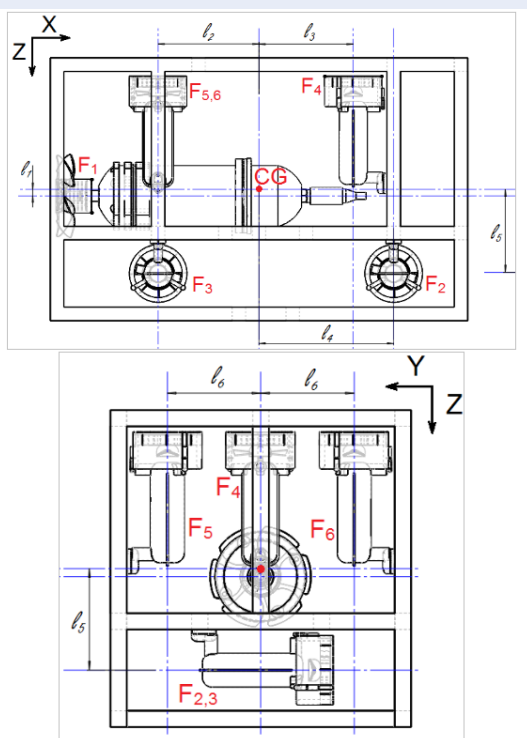

Figure 4: Thruster layout contributes to determine the configuration matrix in side view and front view.

$\mathrm{l}_{4}=200 \mathrm{~mm}, \mathrm{l}_{5}=125 \mathrm{~mm}, \mathrm{l}_{6}=115 \mathrm{~mm}$ as shown in Figure 4.

$$
\begin{aligned}
\tau=B . u= & {\left[\begin{array}{cccccc}
1 & 0 & 0 & 0 & 0 & 0 \\
0 & 1 & 1 & 0 & 0 & 0 \\
0 & 0 & 0 & 1 & 1 & 1 \\
-l_{5} & -l_{5} & 0 & 0 & l_{6} & -l_{6} \\
l_{1} & 0 & 0 & -l_{3} & l_{2} & l_{2} \\
0 & l_{4} & -l_{2} & 0 & 0 & 0
\end{array}\right] } \\
& {\left[\begin{array}{c}
F_{1} \\
F_{2} \\
F_{3} \\
F_{4} \\
F_{5} \\
F_{6}
\end{array}\right] }
\end{aligned}
$$

When ROV moves underwater, its motion would force the amount of surrounding fluid (water) to oscillate with different amplitudes, which is called added mass. In the general dynamic equation (5), $\mathrm{M}$ is the sum of the rigid-body mass inertia matrix $\left(\mathrm{M}_{R B}\right)$ and added mass matrix $\left(\mathrm{M}_{A}\right)$ where $\mathrm{m}, \mathrm{I}$ are ROV's total mass and inertial moment components along $\mathrm{X}, \mathrm{Y}$, $\mathrm{Z}$ axes and vector $\mathrm{r}_{G}=\left[\mathrm{x}_{G}, \mathrm{y}_{G}, \mathrm{z}_{G}\right]^{T}$ is the coordinate of ROV center of gravity. Moreover, due to the fact that ROV is relatively symmetric and moves at low speed, $\mathrm{M}_{A}$ can be simplified into diagonal matrix ${ }^{5}$.

$$
M=M_{R B}+M_{A}
$$




$$
\begin{gathered}
M_{R B}=\left[\begin{array}{cccc}
m & 0 & 0 & 0 \\
0 & m & 0 & -m z_{G} \\
0 & 0 & m & m y_{G} \\
0 & -m z_{G} & m y_{G} & I_{x} \\
m z_{G} & 0 & -m x_{G} & -I_{y x} \\
-m y_{G} & m x_{G} & 0 & -I_{z x} \\
m z_{G} & -m y_{G} \\
0 & m x_{G} \\
-m x_{G} & 0 \\
-I_{x y} & -I_{x z} \\
I_{y} & -I_{y z} \\
-I_{z y} & I_{z}
\end{array}\right] \\
M_{A}=-\operatorname{diag}\left(X_{u}, Y_{v}, Z_{w}, K_{p}, M_{q}, N_{r}\right)
\end{gathered}
$$

Similarly, $\mathrm{C}(\mathrm{v})$ is the total Coriolis and Centripetal matrix of ROV rigid body and added mass, affecting particularly when angular velocities change.

$$
\begin{aligned}
& C(v)=C_{R B}(v)+C_{A}(v) \\
& C_{B}(v)=\left[\begin{array}{cc}
0_{3 \times 3} & C_{12}(v) \\
-C_{12}^{T}(v) & C_{22}(v)
\end{array}\right] \\
& C_{12}(v)\left[\begin{array}{cc}
m\left(y_{G} q+z_{G} r\right) & -m\left(x_{G} q-w\right) \\
-m\left(y_{G} p+w\right) & m\left(z_{G} r+x_{G} p\right) \\
-m\left(z_{G} p-v\right) & -m\left(z_{G} q+u\right)
\end{array}\right. \\
& -m\left(x_{G} r+v\right) \\
& -m\left(y_{G} r-u\right) \\
& m\left(x_{G} p+y_{G} q\right) \\
& C_{22}(v)=\left[\begin{array}{cc}
0 & -I_{y z} q-I_{x z} p+I_{z} r \\
I_{y z} q+I_{x z} p-I_{z} r & 0 \\
-I_{y z} r-I_{x y} p+I_{y} q & I_{x y} r+I_{x y} q-I_{x} p
\end{array}\right. \\
& I_{y z} r+I_{x y} p-I_{y} q \\
& -I_{x z} r-I_{x y} q+I_{x} p \\
& 0 \\
& C_{A}(v)=\left[\begin{array}{ccccc}
0 & 0 & 0 & 0 & -Z_{\dot{w}} w \\
0 & 0 & 0 & Z_{\dot{w}} w & 0 \\
0 & 0 & 0 & -Y_{\dot{v}} v & X_{\dot{u}} u \\
0 & -Z_{\dot{w}} w & Y_{\dot{v}} v & 0 & -N_{\dot{r}} r \\
Z_{\dot{w}} w & 0 & -X_{\dot{u}} u & N_{\dot{r}} r & 0 \\
-Y_{\dot{v}} v & X_{\dot{u}} u & 0 & -M_{\dot{q}} q & K_{\dot{p}} p
\end{array}\right. \\
& \left.\begin{array}{c}
Y_{\dot{v}} v \\
-X_{\dot{u}} u \\
0 \\
M_{\dot{q}} q \\
-K_{\dot{p}} p \\
0
\end{array}\right]
\end{aligned}
$$

The hydrodynamic damping force matrix consists of a linear and quadratic terms where the terms higher than second-order are negligible. With a non-couple motion, a diagonal approximation would be acceptable in most of applications. Although the damping coefficients appear to be challenging to determine, we can make use of strip theory or practical experiments ${ }^{6}$.

$$
\begin{aligned}
D(v)=-\operatorname{diag}\{ & \left.X_{u}, Y_{v}, Z_{w}, K_{p}, M_{q}, N_{r}\right\} \\
-\operatorname{diag}\{ & X_{|u| u}|u|, Y_{|v| v}|V|, Z_{|w| w}|W|, K_{|p| p}|P| \\
& \left.M_{|q| q}|q|, N_{|r| r}|r|\right\}
\end{aligned}
$$

The last part of the dynamic equation is the restoring force matrix, existing as the interaction between buoyant forces based on Archimedes' principle and the force of gravity. As they are expressed in the earthfixed frame, a transformation matrix $\mathrm{g}(\eta)$ must be used to add them to (5) in body-fixed frame.

$$
\begin{aligned}
& g(\eta)= \\
& {\left[\begin{array}{c}
(W-B) \sin \theta \\
-(W-B) \cos \theta \sin \phi \\
-(W-B) \cos \theta \cos \phi \\
-\left(y_{G} W-y_{B} B\right) \cos \theta \cos \phi+\left(Z_{G} W-Z_{B} B\right) \cos \theta \sin \phi \\
\left(z_{G} W-Z_{B} B\right) \sin \theta+\left(X_{G} W-X_{B} B\right) \cos \theta \cos \phi \\
-\left(X_{G} W-X_{B} B\right) \cos \theta \sin \phi-\left(y_{G} W-y_{B} B\right) \sin \theta
\end{array}\right]}
\end{aligned}
$$

\section{ROV model control}

Prior to control the experimental model, simulation using MATLAB Simulink will be studied to investigate the central controller. Due to the difficulty in modelling state parameters and MIMO control, the classical PID controller has been proposed for some reasons such as its simplicity in many applications and positive response. Figure 5 demonstrates the block diagram of closed-loop control system for ROV. There are two mode of maneuvering. Normally, ROV is manipulated by human pilot from an onshore base, but the ability of remaining at a desired depth or heading angle does contribute much to task accomplishment. Therefore, this section focuses on the PID controllers for depth and heading angle, following the block diagram in Figure 5.

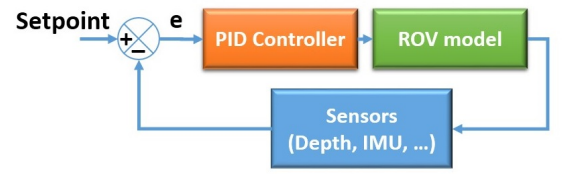

Figure 5: Block diagram of controlling system.

After choosing algorithm for controlling, along with the set of equations (1) and (5), the simulation model 


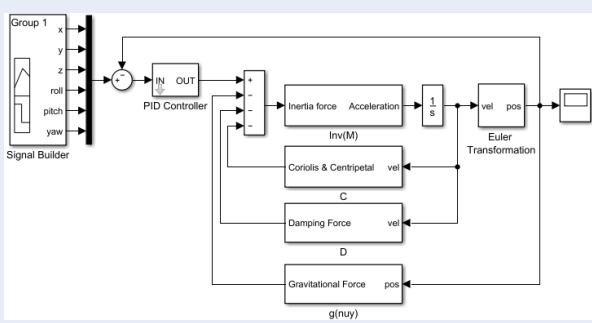

Figure 6: Function block diagram of controlling system in Simulink.

is established to obtain the response of ROV at different setpoints, as shown in Figure 6.

Figure 7 shows the overall system of electronic and electrical devices in ROV. CAN (Controller Area Network) protocol is crucial for communication in this structure. With the $1 \mathrm{Mbps}$ data transfer rate, CAN bus guarantees the response rate for the whole system while eliminating common noise by means of differential signals from twisted pair cable. The central processing unit is Raspberry PI 3 (Model B) with ARM core provides $1 \mathrm{Gbps}$ processing speed, taking charge of major control -and computation; 2 boards ARM STM32F407VGTxx ${ }^{7}$ are used to collect data from sensors and receive commands from Raspberry to drive motors. ROV has to be connected with the onshore station via Ethernet TCP/IP communication. All signals from sensors and camera will be sent and displayed in user interface (GUI) whereas the station transfers input values from joystick to the central processing unit.

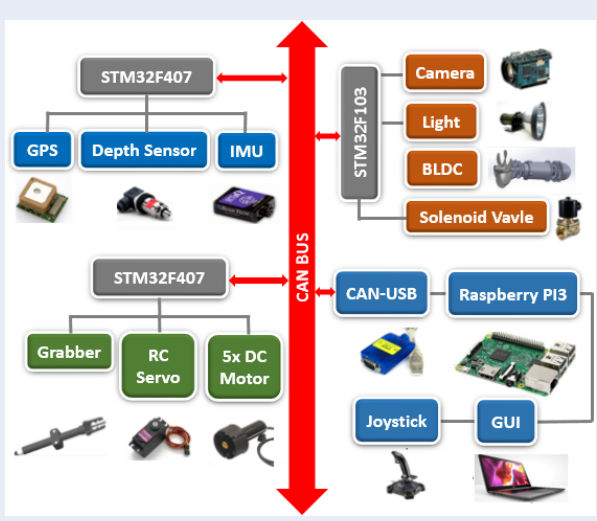

Figure 7: Communication diagram of hardware and electronic components.

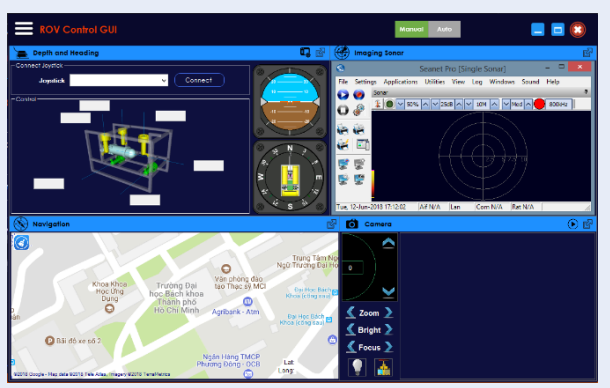

Figure 8: Interactive monitoring interface.

\section{General user interface}

Figure 8 gives us a capture of monitoring screens to visualize how pilots can track the parameters of the vehicle. The software based on Visual Studio platform and C\# programming language allows users to monitor state parameters like the direction of rotation and power of motor (\%), altitude, depth and camera images, etc. Then, the operator can use the integrated function to store data as Excel spreadsheets for further analysis. Besides, after connecting GUI and ROV by setting Ethernet connection, it is easy to maneuver ROV at will with the joystick or to tune the PID coefficient $\left(\mathrm{K}_{p}, \mathrm{~K}_{i}, \mathrm{~K}_{d}\right)$ so that the vehicle's response can reach the set points. Another important key feature is that the pilot can observe the surrounding environment with high quality camera.

\section{RESULTS AND DISCUSSION}

\section{Simulation result}

Based on the model built in previous sections, a set of parameters is inputted into function blocks so as to tune the PID coefficients to receive the most satisfactory response. The limit of force for depth control is $70 \mathrm{~N}$ and that for heading control is $70 \mathrm{Nm}$. Figure 9 and Figure 10 show the output response of simulation, comparing to some desired values. The tuned PID's gain for depth control is $[120,0,180]^{T}$ and that for heading control is $[25,0,0.5]^{T}$.

Both figures indicate good response of the two PID controllers. The steady-state errors are zero and there are almost no overshoots. Assuming that the influence of environmental disturbance is insignificant, the high damping coefficient along $\mathrm{Z}$-axis is responsible for extending the settling time of depth control. When the damping component from $\mathrm{D}(\mathrm{v})$ reach the control output to drive thrusters, the vehicle's acceleration of heave motion, for instance, is terminated, which leads to constant motion. On the other hand, the response of heading control proves to be quite optimistic. 


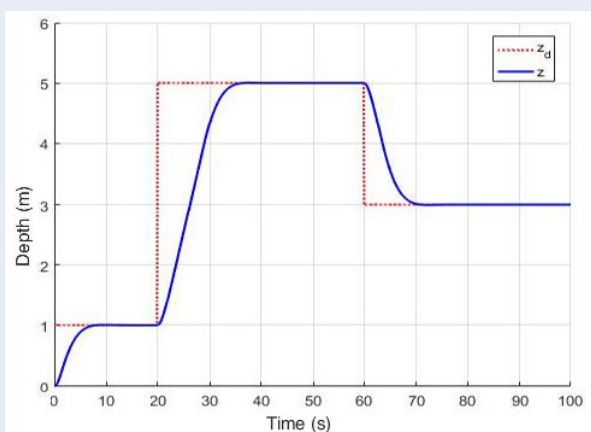

Figure 9: The PID response of auto-depth control.

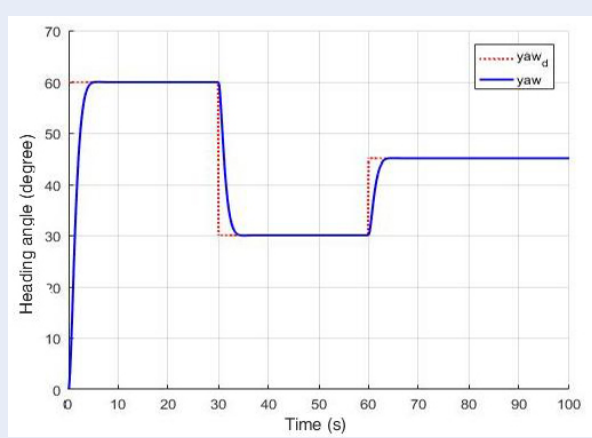

Figure 10: The PID response of auto-heading control.

\section{Simulation result}

The last part of this section comes up with several experiments to verify the operation of ROV based on the designed model and simulation as shown in Figure 11 and Figure 12. The experiments take place in a swimming pool 1.8 meters deep. Power supply and Ethernet communication are transferred via cable from an onshore station. The operator manipulates ROV with joystick and GUI on PC screen in two modes: manual and automatic (depth, heading).

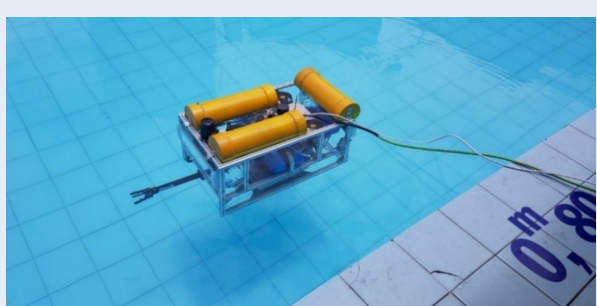

Figure 11: Actual test when ROV floats on water surface.

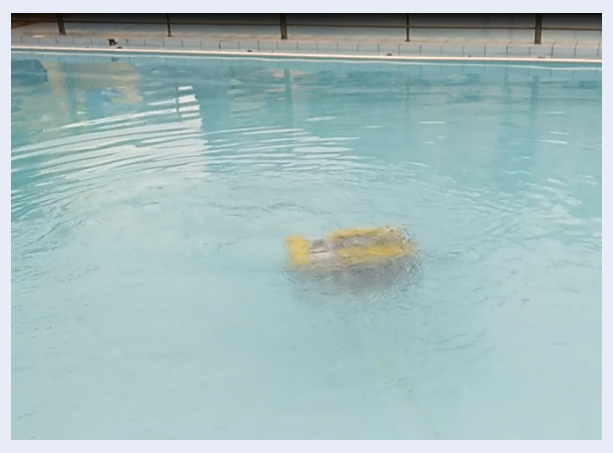

Figure 12: ROV's movement at a desired depth underwater without external forces.

During the experimental process, the response of the control object (ROV) will be displayed on the screen and exported into an Excel every 10 milliseconds. The monitor can use this report function for information analysis afterward, as observed in Figure 13 and Figure 14.

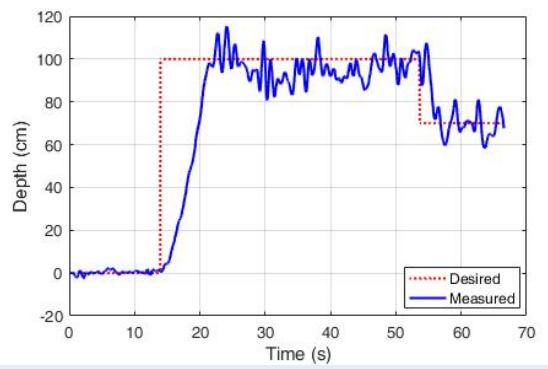

Figure 13: Experimental depth response of ROV with different set-points.

According to the experimental results in Figure 13 and Figure 14, it can be seen that the PID controller give fairly good response, both in terms of the depth and heading control. During the experimental process, some external forces are applied when the heading angle controller is working but the controller keep ROV tracking back to the set point. However, there are still many aspects that need to be improved. Due to limited available devices and equipment, noise measurement contributes substantially to the controller, making the response oscillate around the reference value without being stable. In addition, the design is lack of optimal hydrodynamic profile, which prolongs the depth control settling time (about $8.44 \mathrm{~s})$. 


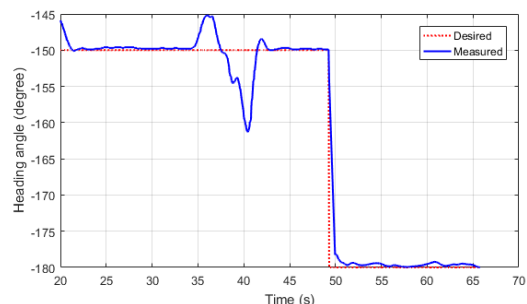

Figure 14: Experimental heading angle response of ROV with different set-points.

\section{CONCLUDING REMARKS}

This paper has presented the research of 6-DOF ROV model which have the ability to move flexibly underwater under the conditions of the experiment. Through mathematical models, simulation process is carried out to evaluate the ability of the controller. In addition, the design of the control system for the actual model and experiments in the pool are also mentioned in order to observe the response of the selected controller when applying from theory into reality.

\section{ACKNOWLEDGEMENT}

This research was funded by The Youth Incubator for Science and Technology Programe, managed by Youth Development Science and Technology Center Ho Chi Minh Communist Youth Union and Department of Science and Technology of Ho Chi Minh City, the contract number is " 04/2019/ HĐ-KHCN-VU" " Also this is supported by Laboratory of Advanced Design and Manufacturing Processes - HCMUT.

\section{CONFLICT OF INTERESTS}

The author declares that this paper has no conflict of interests.

\section{AUTHORS' CONTRIBUTIONS}

Tran Ngoc Huy has d eveloped the proposed algorithm and wrote the manuscript. Huynh Tan Dat implemented hardware configuration, experiments and wrote the manuscript.

\section{ABBREVIATIONS}

ROV: Remotely Operated Vehicle

AUV: Autonomous Underwater Vehicle

PID: Proportional Integral Derivative

DC: Direct current

NED: North - East - Down

MIMO: Multiple Input, Multiple Output

CAN: Controller Area Network

ARM: Advanced RISC Machine

GUI: Gerneral User Interface

6-DOF: 6 degrees of freedom

TCP/IP: Transmission Control Protocol/Internet Protocol

\section{REFERENCES}

1. Budiyono A, Hujjatul A, Setiawan J. Simulation and Dynamic Analysis of Remotely Operated Vehicle (ROV) Using PID Controller for Pitch Movement; 2015.

2. Christ RD, Wernli R. The ROV Manual: A User Guide for Observation Class Remotely Operated Vehicles. 1-320; 2011.

3. Siong CC, Michael L, Low E, Seet G. Software for Modelling and Simulation of a Remotely Operated Vehicle. International Journal of Simulation Modeling. 2006;5:114-125.

4. Fossen TI. Marine Control Systems Guidance, Navigation, and Control of Ships, Rigs and Underwater Vehicles. Marine cybernetics AS. 2002;.

5. Fossen TI. Handbook of Marine Craft Hydrodynamics and Motion Control. New York: Wiley; 2011.

6. Chin CS, Lin WP, Lin JY. Experimental validation of open-frame ROV model for virtual reality simulation and control. J Mar Sci Technol. 2018;23:267-267.

7. Datasheet STMicroelectronics. 


\section{Mô hình hóa, thiết kế và điều khiển Thiết bị lặn vận hành từ xa khảo sát vùng nước nông với chi phí thấp}

\section{Trần Ngọc Huy*, Huỳnh Tấn Đạt}

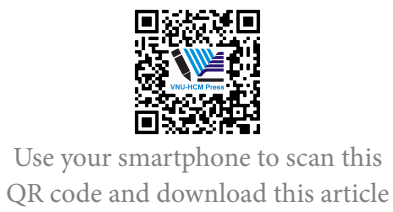

Trường Đai học Bách Khoa,

ĐHQG-HCM

\section{Liên hệ}

Trần Ngọc Huy, Trường Đại học Bách Khoa, ĐHQG-HCM

Email: tnhuy@hcmut.edu.vn

Lịch sử

- Ngày nhận: 15/10/2018

- Ngày chấp nhận: 03/12/2018

- Ngày đăng: 31/12/2019

DOI : 10.32508/stdjet.v3iSI1.722

\section{Check for updates}

\section{Bản quyền}

๑ ĐHQG Tp.HCM. Đây là bài báo công bố mở được phát hành theo các điều khoản của the Creative Commons Attribution 4.0 International license.

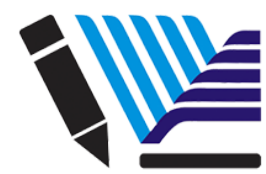

VNU-HCM Press

\section{TÓM TẮT}

Vùng nước nước nông bao gồm ao hồ kênh rạch và sông ngòi chiếm vị thế quan trọng trong nền văn hóa tinh thẩn và kinh tế của người dân Việt Nam suốt chiếu dài lịch sử. Vi vậy, vô số nghiên cứu đã được thực hiện liên quan đến đề tài này với nhiều mục đích, hầu hết trong đó là nâng cao chất lượng cuộc sống và sự an toàn. Với sự hỗ trợ của công nghệ mới, phương tiện hiện đại dần thay thế các phương pháp thông thường để vươn tới tiêu chuẩn cao hơn vể hiệu suất và sự tiện lợi. Bài báo này trình bày các nghiên cứu về thiết kế mô hình và điều khiển thiết bị điểu khiển từ xa dưới nước (ROV) thuộc phòng thí nghiệm trong điẻm quốc gia DCSELAB. Về cơ bản, nó được điều khiển bởi người giám sát dể di chuyển và thực hiện các tác vụ được giao dưới mặt nước. Nguồn cung cấp điện và truyền thông được kết nối nhờ vào trạm trên bờ thông qua hệ thống dây cáp. Có nhiều giai đoạn trong quá trình phát triển một mô hình ROV nguyên bản cần được nghiên cứu kĩ lướng. Trước khi thực hiện thí nghiệm trong môi trường thực tế, mô hình 3D xây dựng trên phần mềm SolidWork và mô hình toán được phân tích bằng MATLAB Simulink tạo ra một đối tượng tuyến tính mô phỏng để áp dụng bộ điều khiển cổ điển PID và kiểm nghiệm khả năng vận hành thông qua quá trình mô phỏng. Khung ngoài bảo vệ các thành phần khỏi hư hại và giúp cố định chúng trong khi thiết kế bố trí đônng cơ từ mô phỏng cho phép di chuyển linh hoạt. Hệ thống cảm biến và máy ghi hình thu thập dữ liệu để xem tại chỗ hoặc lưu lại để phân tích sâuu hơn. Sau khi tập hợp tất cả các phần tử, chúng tôi thực hiện thí nghiệm ở đáy hổ bơi tương tự điều kiện khảo sát vùng nước nông. Kết quả thí nghiệm khả qua chứng tỏ khả năng của bộ điểu khiển ngay cả khi có sự hiện diện của tác nhân bên ngoài.

Từ khoá: Phương tiện điều khiển từ xa, bộ điều khiển khuếch đại vi tích phân (PID), rô-bốt dưới nước
Trích dẫn bài báo này: Huy $\mathrm{T} N$, Đạt $\mathrm{H} \mathrm{T}$. Mô hình hóa, thiết kế và điều khiển Thiết bị lặn vận hành từ xa khảo sát vùng nước nông với chi phí thấp. Sci. Tech. Dev. J. - Eng. Tech.; 2(SI1):SI49-SI56. 